\title{
The effect of paternalistic alternatives on attitudes toward default nudges
}

\author{
WILLIAM HAGMAN
}

Department of Behavioral Science and Learning, Linköping University, Linköping, Sweden ARVID ERLANDSSON

Department of Behavioral Science and Learning, Linköping University, Linköping, Sweden STEPHAN DICKERT

School of Business and Management, Queen Mary University of London, London, UK and

Klagenfurt University, Klagenfurt, Austria

GUSTAV TINGHÖG

Department of Management and Engineering, Division of Economics, Linköping University, Linköping, Sweden DANIEL V ÄSTFJ ÄLL*

Department of Behavioral Science and Learning, Linköping University, Linköping, Sweden and

Decision Research, Eugene, OR, USA

\begin{abstract}
Nudges are increasingly being proposed and used as a policy tool around the world. The success of nudges depends on public acceptance. However, several questions about what makes a nudge acceptable remain unanswered. In this paper, we examine whether policy alternatives to nudges influence the public's acceptance of these nudges: Do attitudes change when the nudge is presented alongside either a more paternalistic policy alternative (legislation) or a less paternalistic alternative (no behavioral intervention)? In two separate samples drawn from the Swedish general public, we find a very small effect of alternatives on the acceptability of various default nudges overall. Surprisingly, we find that when the alternative to the nudge is legislation, acceptance decreases and perceived intrusiveness increases (relative to conditions where the alternative is no regulation). An implication of this finding is that acceptance of nudges may not always automatically increase when nudges are explicitly compared to more paternalistic alternatives.
\end{abstract}

Submitted 9 July 2018; revised 29 April 2019; accepted 01 May 2019

\footnotetext{
* Correspondence to: Daniel Västfjäll, Department of Behavioral Science and Learning, Linköping University, Linköping, Sweden. Email: daniel.vastfjall@liu.se
} 
The idea that barely noticeable changes in how choice alternatives are presented (i.e., nudges) can help people to make better decisions is viewed as a promising policy option by many. Nudges, such as strategic use of default rules, are therefore increasingly being proposed and used as a policy tool by government agencies around the world (Whitehead et al., 2014; Halpern \& Sanders, 2016). Compared to more traditional policy tools such as mandates and taxes, nudges are typically viewed as less paternalistic. Still, ethical concerns have been raised that the use of nudges is manipulative and thereby not as liberty preserving as it is often portrayed (e.g., see Bovens, 2009; Hausman \& Welch, 2010; Whitman \& Rizzo, 2015). This debate has spurred research exploring if and when individuals judge nudges as acceptable and nonintrusive to freedom of choice (Hagman et al., 2015; Jung \& Mellers, 2016; Sunstein, 2016; Reisch et al., 2017; Sunstein et al., 2017a; Loibl et al., 2018). Overall, these studies have shown that the acceptability of the use of nudges in public policy tends to be moderate to high across most countries. Common to these studies, however, is that they have not considered that the (un)stated policy alternative (i.e., legislation or no regulation) is likely to affect the evaluation of acceptability. A nudge intervention might seem like a good idea in the abstract, but be less appealing when placed in context. Conversely, the appeal of a nudge intervention may only become apparent in the context of a worse alternative. For instance, when judged separately from any salient alternative, a default intervention intended to increase organ donation may seem paternalistic. However, when compared to the alternative of legislation that all must donate their organs, the nudge intervention may now appear as a very good alternative. Put differently, preference reversals are likely to occur when nudges are evaluated in the context of an alternative (joint evaluation) compared to in isolation (separate evaluation; see Bazerman et al., 1992; Hsee et al., 1999). Here, we explore the extent to which attitudes toward the use of nudges in public policy are affected by stated alternatives to that nudge.

Understanding when and why people judge nudges as acceptable or not is critical since any public policy necessitates some level of public support in order to achieve its objective (Page \& Shapiro, 1983; Tannenbaum et al., 2017). Moreover, nudges may backfire and lead to adverse effects on the type of behavior they are trying to promote if they are implemented despite a lack of public support (Arad \& Rubenstein, 2017). When exploring what aspects influence attitudes toward nudges, several conceptual distinctions that affect attitudes toward nudges have been highlighted. For example, nudges categorized as pro-self (i.e., focusing on enhancing private welfare) are preferred to nudges that are categorized as pro-social (i.e., focusing on enhancing social welfare; Hagman et al., 2015). Similarly, nudges that target 
reflective or conscious thinking are viewed as more acceptable compared to nudges that play on individuals' intuitive thinking (Felsen et al., 2013; Jung \& Mellers, 2016; Sunstein, 2016). Nudges that are educational and make information more salient are also preferred compared to nudges that take advantage of peoples' inattention and laziness (Sunstein, 2017a).

In addition to exploring general attitudes, some studies have also explored the extent to which individual differences in worldviews/values systematically influence nudge attitudes. Surprisingly, political affiliation is generally a weak predictor of attitudes toward nudges (Reisch \& Sunstein, 2016). Some evidence, however, suggests that people with a 'communitarian worldview' are more likely to exhibit positive nudge attitudes compared to those with a more individualistic worldview (Hagman et al., 2015). Similarly, people who score high on libertarian values are also more likely to disapprove of nudges in public policy (Jung \& Mellers, 2016). Such findings are in line with theories in social psychology suggesting that people with a more pronounced individualistic worldview should be increasingly resistant to external control and thus be less accepting of policies that can be seen as infringements of autonomy (Kahan \& Braman, 2006).

Common to all previous studies that have explored attitudes toward nudges is that they have not explicitly specified what, if any, the alternative policy approach is. Information about the relevant policy alternative will arguably influence attitudes toward nudge interventions. We argue that evaluations concerning the acceptability and intrusiveness of nudges are made just as we make other judgments in life, where the 'goodness' or 'badness' of an outcome often is evaluated relative to a reference point (Slovic et al., 2002; Kahneman, 2011). More specifically, we believe that making the more paternalistic alternative (e.g., legislation) salient will make nudges appear more appealing (i.e., more acceptable and less intrusive). Similarly, the use of nudges should appear as less appealing when it is compared to a policy that claims to effectively change nothing. This prediction is based on research by Sunstein (2017a) that reports data from a direct test of approval of nudges (default rule with an opt-out option) versus legislation (making mandatory) for three initiatives: savings, safe sex education and education about intelligent design. Approval for nudges over legislation differed by $32-50 \%$, with a majority always preferring nudges. Thus, nudges appear to be more accepted than bans because "mandates and bans face objections that do apply to nudges. Because people care about agency and want to maintain it, they will be skeptical of initiatives that eliminate it, even as they acknowledge that in some domains, coercion is amply justified" (Sunstein, 2017b, p. 32). Sunstein points out that many oppose legislation as such, but that for nudges people have no general view, but instead construct attitudes based on the information contained in the nudge itself. 
Thus, we predict that explicitly stating information about policy alternatives will influence the extent to which nudges are viewed as acceptable and nonintrusive. This prediction is also in line with a recent study by Davidai and Shafir (2018), who found that people are less likely to endorse nudges when alternative nudges are presented simultaneously (joint evaluation) rather than separately (separate evaluation). In two studies conducted using representative Swedish samples, we explore the extent to which attitudes toward nudges systematically change when presented alongside a more paternalistic policy alternative (legislation) and a less paternalistic alternative (no regulation). We predict that nudges presented with a more paternalistic alternative will have greater acceptability and be perceived as less intrusive compared to the same nudge presented with a less paternalistic alternative. We examine this prediction for both pro-social and pro-self nudges. In general, we expect that pro-self nudges will be seen as more acceptable and less intrusive than pro-social nudges. Because of this, we predict that the effect of a given alternative will be greater for pro-social nudges. In addition, we also explore how individual differences depend on people's worldview and influence the malleability toward the use of nudges in public policy.

\section{Study 1}

\section{Method}

\section{Sample and materials}

A web-based survey administrated by CMA Research (a data collection company) was sent to a diverse sample of the adult Swedish population (aged 20-75 years). In total, 608 participants completed the survey $(52.7 \%$ female, mean age 41.4 years). Thirty-three participants did not complete the full survey and were included in the analysis of overall acceptance, but were not included in the analysis of individual differences. The sample was drawn from a representative pool of the general population in Sweden with slightly greater income and education than average. Participants received a small amount of monetary compensation (approximately US\$1.50) for completing the survey.

The survey started with a general introduction that informed participants that behavioral interventions in public policy are becoming increasingly common and that the goal of the survey was to assess opinions among the general public about such interventions. All participants were then presented with a series of experimental tasks in which four nudge scenarios were included (in a random order). 
All of the scenarios are shown in Box 1. Each of these scenarios involved the strategic use of a default rule (i.e., changing opt in to opt out) in a specific policy area. The nudge scenarios were chosen to represent key policy areas and to include a common type of nudge intervention presented in the nudge literature (e.g., see Thaler \& Sunstein, 2008; Sunstein, 2017b; Szaszi et al., 2017). The scenarios followed the same basic structure. The first sentence presented the policy issue at hand and was then followed by a description of a suggested nudge intervention that involved strategic use of a default rule. Next, the intended goal of the intervention was stated (e.g., "the goal of this intervention is to increase the number of individuals who are organ donors").

Box 1. Nudge scenarios translated from Swedish. ${ }^{a}$

\section{Organ donation (pro-social nudge)}

There is a lack of organ donors in Sweden. In order to become an organ donor, it is now required that the individual him- or herself makes an active choice and announces his/her will to the healthcare service. If no active choice is made, the individual is assumed to not want to donate any organs in case of an accident. Studies have shown that many people want to register as donors, but few people actually do so. A proposed intervention to increase the number of organ donors is that everyone is automatically registered as organ donors. This means that people who do not want to be organ donors must actively contact the healthcare service and state that they would like to unregister.

The goal of this intervention is to increase the number of individuals who are organ donors.

[The alternative to this intervention is to do nothing at all to increase the number of individuals who are organ donors.]

\{The alternative to this intervention is to introduce legislation that makes everyone an organ donor without the possibility to unregister.\}

\section{Climate compensation (pro-social nudge)}

Carbon dioxide emissions in connection with air travel have a negative impact on the climate. To compensate for this negative impact, there is usually a voluntary climate compensation fee that airline travelers can choose to pay. This fee goes to projects aimed at reducing carbon dioxide emissions corresponding to the emissions caused by the air travel. If no active choice is made, the individual is assumed to not want to pay the climate compensation fee. Studies have shown that many people want to climate compensate when they travel, but few people actually do so. A 
proposed intervention to increase the number of people that climate compensate is that compensation is included in the price when you buy the journey. This means that people who do not want to pay the compensation fee must actively contact the travel agency and state that they do not want to pay the fee.

The goal of this intervention is to increase the number of individuals who compensate for air travel.

[The alternative to this intervention is to do nothing at all to increase the number of individuals who compensate for air travel.]

\{The alternative to this intervention is to introduce legislation that makes it mandatory to pay a compensation fee for air travel.\}

\section{Retirement savings (pro-self nudge)}

Most Swedes save too little for their retirement today, which can lead to a difficult financial situation when getting older. Individuals today must make an active choice to save extra for their retirement. If no active choice is made, it is assumed that the individual does not want to save extra for their retirement. Studies have shown that many people want to save more for retirement, but few people actually do so. A common way to increase your retirement savings is to spend a greater part of the salary on retirement savings. A proposed intervention to increase individuals' retirement savings is to automatically increase the amount selected for retirement with each wage increase. This means that people who do not want to increase the amount selected for retirement with each wage increase must contact their employer themselves and state that they do not want to increase retirement savings.

The goal of this intervention is to increase individuals' retirement savings.

[The alternative to this intervention is to do nothing at all to increase individuals' retirement savings.]

$\{$ The alternative to this intervention is to introduce legislation that makes it mandatory to increase the amount selected for retirement with each wage increase.

Cancer screening (pro-self nudge)

In Sweden, there are many who die from cancer who could have survived if the cancer had been discovered earlier. To get a cancer screening, it is now necessary for the individual to make an active choice and book a cancer screening themselves. If no active choice is made, it is assumed that the individual does not want to get a cancer screening. Studies have shown that many people want to get screened for cancer, but few people actually do so. A 
proposed intervention to increase the number of people who participate in cancer screenings is that everyone is automatically called to a cancer screening in the year they turn 40 . This means that people who do not want to be called for a cancer screening must actively contact the healthcare service and state that they do not want to be called for a cancer screening.

The goal of this intervention is to increase the number of individuals who get screened for cancer.

[The alternative to this intervention is to do nothing at all to increase the number of individuals who get screened for cancer.]

\{The alternative to this intervention is to introduce legislation that makes it mandatory to get a cancer screening.

${ }^{a}$ The alternative is added to the control condition in [] for the no-regulation condition and in \{\} for the legislation-as-alternative condition.

Following each scenario, respondents were asked: Acceptability: "Do you find the described policy acceptable?" (yes or no), and Intrusiveness: "Do you think that the described policy restricts the individual's freedom of choice?" (yes or no). These measures are our main dependent variables in the subsequent analyses.

In order to measure individual differences related to ideological worldview, we included the Cultural Cognition Short Scale (Kahan, 2014), which measures whether individuals are more or less prone to an individualistic or communitarian worldview (e.g., "The government interferes far too much in our everyday lives") and the grid subscale with six items (1-4 Likert scale) measuring whether individuals are more or less prone to a hierarchical or egalitarian worldview (e.g., "Our society would be better off if assets were more evenly distributed"). Participants also answered the decision-style scale (Hamilton et al., 2016), which measures the extent to which individuals make intuitive versus analytical decisions. The rational subscale had five items (1-5 Likert scale; e.g., "I prefer to gather all of the necessary information before committing to a decision"), and the intuitive subscale also had five items (1-5 Likert scale; e.g., "I rely on my first impressions when making decisions"). Additional measures included a measure of confidence in the present Swedish government (1 (not at all)-5 (completely), with the possibility to answer that they did not care about the subject) and political orientation ( 1 (far to the left) -7 (far to the right)) along with measures of age, gender and education.

\section{Experimental design}

The participants were randomly allocated to one of three conditions (legislation as alternative, no regulation and control) in a between-subjects 
Table 1. Descriptive statistics of participants for each condition.

\begin{tabular}{lllll}
\hline \hline & Control & No regulation & Legislation as alternative & Total \\
\hline$n$ & 219 & 209 & 213 & 641 \\
Female & $58 \%$ & $53 \%$ & $47 \%$ & $53 \%$ \\
Mean age (years) & 41.1 & 41.0 & 42.5 & 41.4 \\
\hline \hline
\end{tabular}

design. Table 1 shows the numbers of participants and demographics by condition.

In the legislation-as-alternative condition, the participants were informed that the alternative to the suggested intervention was to introduce legislation to enforce a certain behavior instead of merely encouraging it. Moreover, participants were informed that if the default change was not accepted, then legislation would be adopted.

In the no-regulation condition, participants were informed that the alternative to each suggested intervention was "to do nothing at all" to encourage the behavior. Furthermore, participants were explicitly informed after each scenario that if the intervention was not accepted, then nothing else would be done to solve the problem that the intervention was designed to handle.

In the control condition, participants were only informed that this survey was performed in order to measure the public's attitude toward different interventions to increase various behaviors. No additional information about alternatives to the intervention was given.

Based on Hagman et al. (2015), two nudge policies were classified a priori as pro-social (organ donation and climate compensation) and two nudge policies were classified as pro-self (retirement saving and cancer screening).

\section{Results and discussion}

\section{Effects of alternative conditions}

The answers to each of the four scenarios were summed to create a rate of acceptance measure ranging from 0 (not accepting any of the nudges) to 4 (accepting every nudge). An intrusiveness rate measure was created in the same way. Figure 1 presents the effect of alternatives across all four scenarios. A $\chi^{2}$-test was conducted to examine whether there was any difference in the proportion of participants that accepted the nudge (acceptance rate) between the alternative conditions. Across conditions, no significant difference for acceptance rate was found $\left(\chi^{2}(8)=8.78, \mathrm{p}=0.361\right)$. However, intrusiveness ratings differed between conditions $\left(\chi^{2}(8)=16.49, \mathrm{p}=0.036\right)$, such that the legislation-as-alternative condition was judged by more participants to be 
The effect of paternalistic alternatives on attitudes toward default nudges 103 4.00

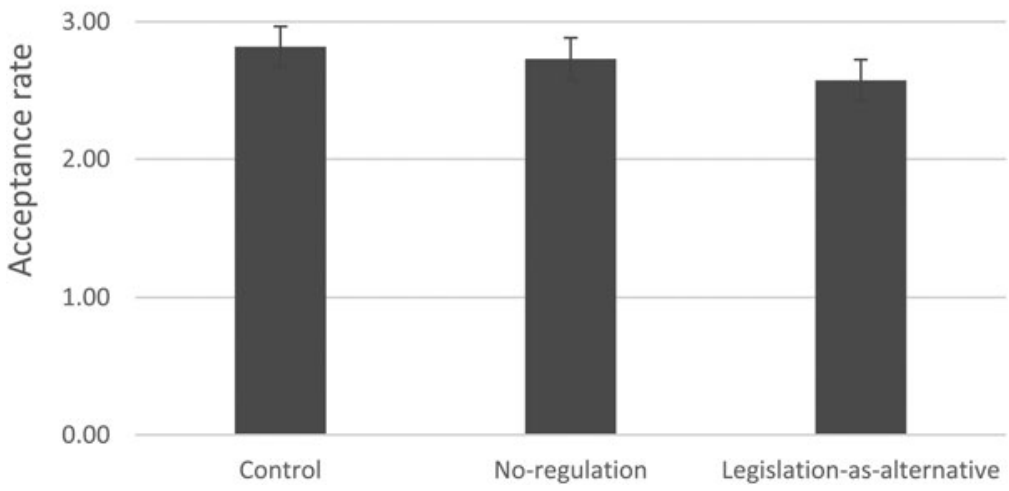

Figure 1. Acceptance rates of nudges divided by condition. Error bars are $95 \%$ confidence intervals.

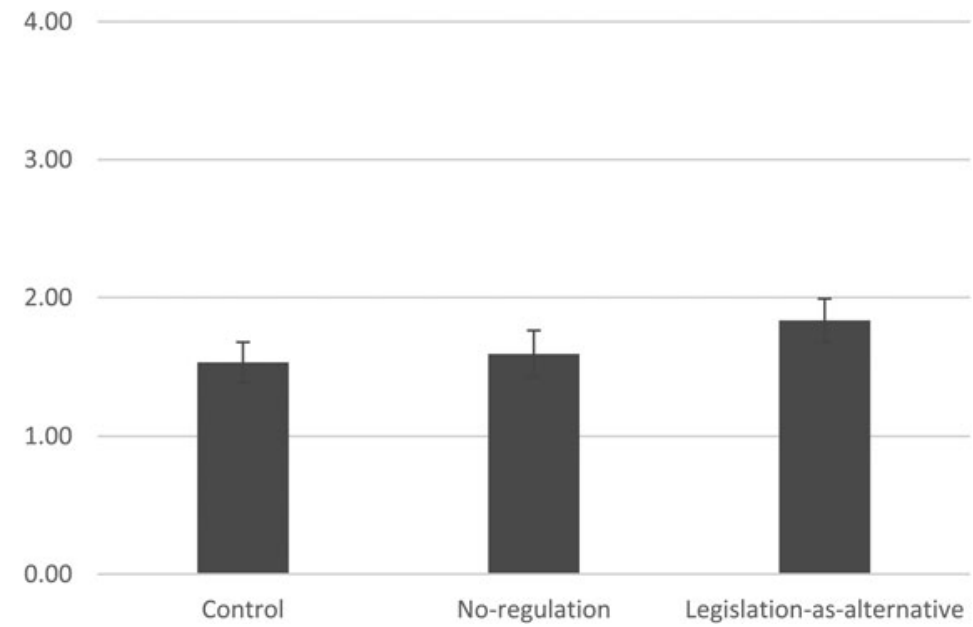

Figure 2. Intrusiveness rates of nudges divided by condition. Error bars are $95 \%$ confidence intervals.

intrusive than both the no-regulation condition and control conditions (Figure 2). Thus, we find no effect of our main manipulation on acceptability when we had expected that the legislation-as-alternative manipulation would be the nudge condition accepted by most participants. We also expected that the nudges in the legislation-as-alternative manipulation would be seen as 
the least restrictive by a majority of the participants. Instead, we find the opposite result.

\section{Effects of pro-social versus pro-self domain}

The two scenarios a priori categorized as pro-self were more accepted $(\mathrm{M}=1.41, n=631)$ than pro-social scenarios $(\mathrm{M}=1.29, n=629)\left(\chi^{2}(4)=48.81\right.$, $\mathrm{p}<0.001)$. Furthermore, pro-self scenarios were perceived as less intrusive $(\mathrm{M}=0.76, n=631)$ than pro-social scenarios $(\mathrm{M}=0.89, n=629)\left(\chi^{2}(4)=69.95\right.$, $\mathrm{p}<0.001)$.

Figures 3 and 4 present the acceptance and intrusiveness rates across the alternative conditions and pro-social/pro-self nudges. As can be seen, there are no interactions and the overall pattern from our main findings holds for both pro-social and pro-self domains.

\section{Effects of individual differences}

In order to investigate individual factors that affect acceptance rates, a multiple regression was conducted (Table 2). In the regression, a dummy variable for the no-regulation condition (1/0) and legislation-as-alternative condition (1/0) and a dummy for higher education (1/0) were included along with control variables for age, gender, individualism, egalitarianism, intuitive and rational decision style, political orientation and confidence in the government.

The results show that $12.4 \%$ of the variance could be explained with two variables $(\mathrm{F}(11,584)=7.505, \mathrm{p}<0.001)$ where the acceptance rate was lower for more individualistic participants $(\beta=-0.082, \mathrm{p}<0.001)$ and more egalitarian participants had a higher acceptance rate $(\beta=0.051, \mathrm{p}=0.001)$, with no other significant effects for the other variables.

A similar analysis was run for intrusiveness (Table 3). That analysis showed that $7.1 \%$ of the variance could be explained with three variables $(\mathrm{F}(11,584)=4.036, \mathrm{p}<0.001)$ where the intrusiveness rate was higher in the legislation-as-alternative condition $(\beta=0.228, \mathrm{p}=0.048)$ and the intrusiveness rate was higher for more individualistic participants $(\beta=0.060, \mathrm{p}<0.001)$ and more egalitarian participants had a lower intrusiveness rate $(\beta=-0.040$, $p=0.019$ ), with no other significant effects for the other variables.

We expected that more individualistic respondents would be more accepting of nudges in the legislation-as-alternative condition (to avoid the legislation) and less accepting when the alternative was to do nothing (no-regulation condition). Separate regressions for each condition show that respondents who scored higher on the cultural cognition worldview group scale (i.e., those who are more individualistic) are significantly less accepting of the nudges in both the control condition $(\mathrm{p}=0.003)$ and in the no-regulation condition $(\mathrm{p}<0.001)$. However, this was not the case for the legislation-as-alternative 


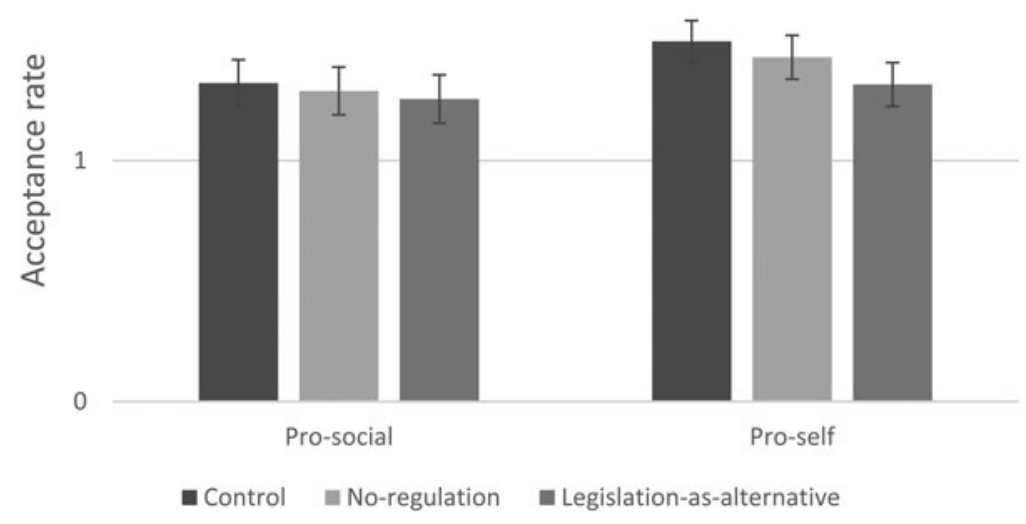

Figure 3. Acceptance rates of pro-social and pro-self nudges divided by condition. Error bars are $95 \%$ confidence intervals.

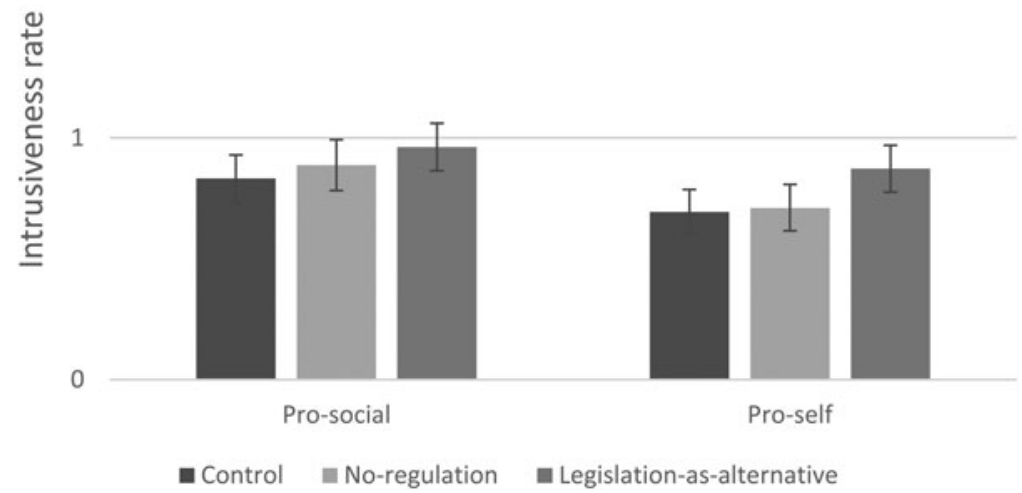

Figure 4. Intrusiveness rates of pro-social and pro-self nudges divided by condition. Error bars are $95 \%$ confidence intervals.

condition $(\mathrm{p}=0.106)$. Furthermore, respondents who scored higher on the cultural cognition worldview grid scale (i.e., more egalitarian) were significantly more accepting of nudges in both the control alternative condition $(\mathrm{p}=0.022)$ and in the no-regulation condition $(\mathrm{p}=0.008)$, but not in the legislation-asalternative condition $(\mathrm{p}=0.300)$. Regarding the other individual difference 
Table 2. Linear regression analyses exploring the influences of individual differences on acceptance rates.

\begin{tabular}{lrrrrr}
\hline \hline & \multicolumn{4}{c}{ Confidence interval } \\
\cline { 3 - 4 } & $\beta$ & Lower bound & Upper bound & $\beta$ (standardized) & p-value \\
\cline { 3 - 4 } & -0.110 & -0.321 & 0.100 & -0.046 & 0.303 \\
No-regulation (dummy) & -0.196 & -0.404 & 0.011 & -0.083 & 0.064 \\
Legislation (dummy) & -0.083 & -0.260 & 0.095 & -0.037 & 0.361 \\
Higher education (dummy) & -0.066 & -0.248 & 0.116 & -0.029 & 0.478 \\
Female & -0.006 & -0.012 & 0.001 & -0.071 & 0.073 \\
Age & -0.082 & -0.111 & -0.053 & -0.249 & $<0.001$ \\
Individualism & 0.051 & 0.021 & 0.082 & 0.154 & 0.001 \\
Egalitarian & 0.027 & 0.000 & 0.055 & 0.080 & 0.054 \\
Rational decision style & 0.015 & -0.011 & 0.042 & 0.047 & 0.259 \\
Intuitive decision style & 0.029 & -0.041 & 0.099 & 0.039 & 0.421 \\
Political orientation & 0.021 & -0.067 & 0.109 & 0.022 & 0.641 \\
Confidence in the government & & & & & \\
\hline \hline
\end{tabular}

Table 3. Linear regression analyses exploring the influences of individual differences on intrusiveness rates.

Confidence interval

$\beta \quad$ Lower bound Upper bound $\beta$ (standardized) $\quad$-value

\begin{tabular}{lrrrrr}
\hline No-regulation (dummy) & 0.004 & -0.114 & 0.223 & 0.001 & 0.974 \\
Legislation (dummy) & 0.228 & -0.226 & 0.454 & 0.092 & 0.048 \\
Higher education (dummy) & 0.042 & 0.002 & 0.235 & 0.018 & 0.671 \\
Female & -0.135 & -0.152 & 0.064 & -0.057 & 0.183 \\
Age & 0.002 & -0.333 & 0.009 & 0.018 & 0.662 \\
Individualism & 0.060 & -0.006 & 0.091 & 0.172 & $<0.001$ \\
Egalitarian & -0.040 & 0.028 & -0.007 & -0.112 & 0.019 \\
Rational decision style & -0.006 & -0.073 & 0.024 & -0.017 & 0.681 \\
Intuitive decision style & 0.014 & -0.037 & 0.043 & 0.041 & 0.347 \\
Political orientation & 0.000 & -0.015 & 0.077 & 0.000 & 0.994 \\
Confidence in the government & 0.012 & -0.076 & 0.108 & 0.012 & 0.807 \\
& & & & & \\
\hline
\end{tabular}

measures, no systematic pattern emerges. For judged intrusiveness, more individualistic respondents find the nudges to be significantly more restricting to freedom of choice in the no-regulation condition $(\mathrm{p}=0.025)$, but not for the other conditions. These results suggest that both individualists and egalitarians are affected by the presented alternative. 
In summary, Study 1 showed, in contrast to our hypothesis, that there was no difference in acceptance when we provided explicit information about the alternative, and there was a difference in the unexpected direction for perceived intrusiveness to freedom of choice. How can this result be understood? Before addressing other possible theoretical explanations, we must address a potential methodological limitation: that the manipulation of alternatives was not strong enough. Given the prevalence and strength of effects of alternatives documented elsewhere in the judgment and decision-making literature (e.g., Kahneman \& Tversky, 1979; Tversky \& Kahneman, 1992; Fredrick et al., 2009; Hsee \& Zhang, 2010; Kahneman, 2011) there are good reasons to think that our manipulation should have worked as intended. However, given the lack of effect of our manipulation, we conducted a direct replication in Study 2 that included manipulation checks as well as different dependent variables (interval scales instead of binary choices) for both acceptance and intrusiveness.

\section{Study 2}

\section{Sample and materials}

A web-based survey administrated by the same data collection company as in Study 1 was sent to a diverse sample (different from Study 1) of the adult Swedish population (aged 18-65 years). In total, 962 participants completed the survey $(54.9 \%$ female, mean age 41.3 years). The sample was drawn from a representative pool of the general population in Sweden, with slightly higher income and education than average. Participants received a small monetary compensation (approximately US\$1.50) for completing the survey. The survey for Study 2 had the same experimental design and nudge scenarios as in Study 1, with the addition of an attention check and a manipulation check and a new response format for the two main dependent variables. Moreover, participants answered the same worldview and decision-style scales as in Study 1. Information about age, gender and education was also collected. Table 4 shows the demographics for each condition.

Following each scenario, respondents were asked to rate: (1) acceptability: "Do you find the described policy acceptable?" where the participants could circle any number between -3 (totally unacceptable) and 3 (totally acceptable); and (2) intrusiveness: "Do you think that the described policy restricts the individual's freedom of choice?" with a -3 (totally unrestricting) to 3 (totally restricting) format. These measures are our main dependent variables in the subsequent analyses.

In addition, we measured attitudes toward the goal of the intervention ("Is it desirable to achieve to goal of $x$ ?" 1 (not at all)-5 (very) with a possibility to 
Table 4. Descriptive statistics of participants for each condition.

\begin{tabular}{lllll}
\hline \hline & Control & No-regulation & Legislation-as-alternative & Total \\
\hline$n$ & 230 & 227 & 235 & 692 \\
Correct on manipulation & $20 \%$ & $36 \%$ & $72 \%$ & $43 \%$ \\
Female & $55 \%$ & $54 \%$ & $55 \%$ & $55 \%$ \\
Mean age (years) & 41.4 & 41.1 & 41.3 & 41.3 \\
\hline \hline
\end{tabular}

answer that they did not care about the subject). Here, an attention check was administrated with the same response format (the participants were given a number they should provide in order to show that they were attentive). The central manipulation check to assess whether the alternative manipulation was successful consisted of the question "What was the alternative given to the suggestion you have answered in this survey?" with the possibility to answer: "No alternative was given" (correct in the control condition), "The alternative was to do nothing to affect people's behavior" (correct in the noregulation condition) or "The alternative was to introduce legislation to affect people's behavior" (correct in the legislation-as-alternative condition). As can be seen in Table 4, a majority of the participants in the legislation-asalternative condition $(72 \%)$ passed the manipulation check, whereas fewer passed the manipulation check for both the no-regulation condition $(36 \%)$ and the control condition (20\%). In the subsequent analyses, we therefore include pass/fail on the manipulation check as a between-subjects variable.

\section{Results and discussion}

\section{Effects of alternative conditions}

The answers for each of the four scenarios were added together to create a sum of acceptance measures ranging from -12 (very unaccepting) to 12 (very accepting). An intrusiveness sum measure was created in the same way. Figure 5 presents the effect of alternatives on acceptance across all four scenarios. A two (manipulation check; passed or failed) by three conditions (control, no regulation, legislation as alternative) analysis of variance was conducted to examine whether there was any difference in acceptance rate between the alternative conditions. A main effect across conditions was found with a significant difference for acceptance rate $(F(2,686)=9.855$, $\mathrm{p}<0.001, \eta=0.028)$, where the no-regulation condition had the highest acceptance rate $(n=227, \mathrm{M}=4.61, \mathrm{SD}=4.58)$ with the control condition $(n=230, \mathrm{M}=4.50, \mathrm{SD}=4.64)$ in the middle and the legislation-as-alternative condition with the lowest acceptance rate $(n=235, \mathrm{M}=3.28, \mathrm{SD}=4.82)$. 
The effect of paternalistic alternatives on attitudes toward default nudges 109

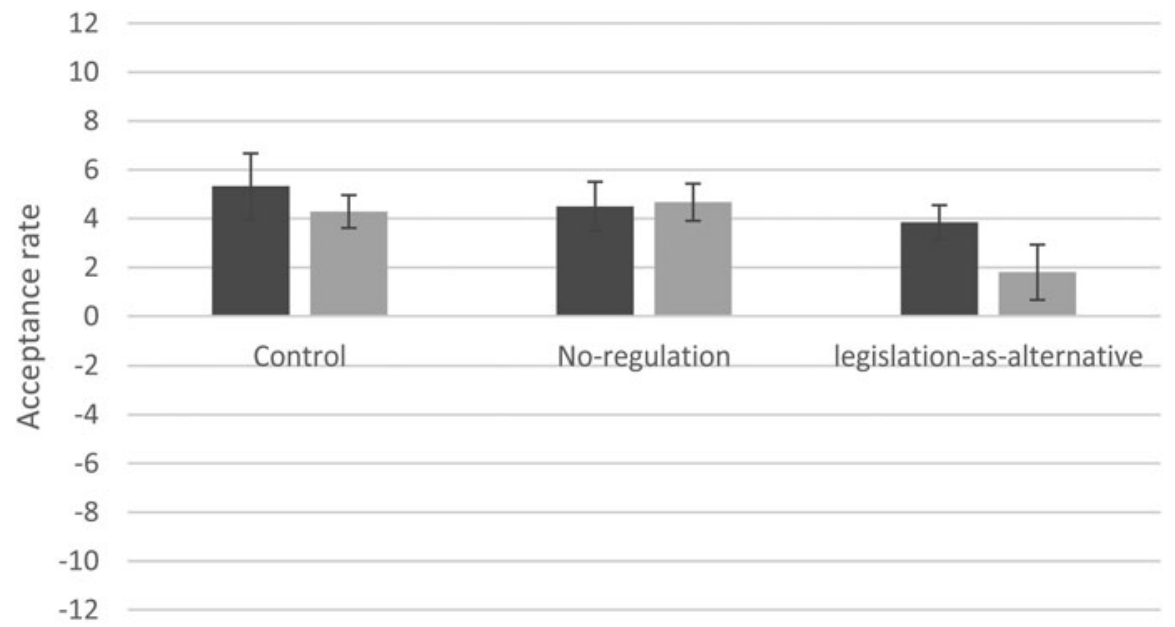

Passed manipulation check Eailed manipulation check

Figure 5. Acceptance rates for each condition and manipulation check. Error bars are $95 \%$ confidence intervals.

A Sidak post-hoc test shows that the participants in the legislation-as-alternative condition were significantly less accepting compared to both the control condition (mean difference: $-1.98, \mathrm{p}<0.001$ ) and the no-regulation condition (mean difference: $-1.76, \mathrm{p}=0.001$ ), and there is no difference between the other conditions (mean difference: 0.223, $\mathrm{p}=0.960$ ). A significant main effect of the manipulation check was also found for acceptance rate $(\mathrm{F}(1,686)=5.812, \mathrm{p}=0.016, \eta=0.008)$, where participants who answered correctly on the manipulation check in general had a greater acceptance rate $(\mathrm{M}=4.26, \mathrm{SD}=4.69)$ compared to participants who answered incorrectly $(\mathrm{M}=4.02, \mathrm{SD}=4.74)$. No significant interaction effect between condition and manipulation check was found $(\mathrm{F}(2,686)=2.824, \mathrm{p}=0.060, \eta=0.008)$.

Figure 6 presents the effects of alternatives on intrusiveness across all four scenarios. A main effect across conditions was found with a significant difference for intrusiveness rate $(\mathrm{F}(2,686)=6.349, \mathrm{p}=0.002, \eta=0.018)$, where the no-regulation condition had the lowest intrusiveness rate $(n=227, \mathrm{M}=-2.18$, $\mathrm{SD}=4.84)$ with the control conditions $(n=230, \mathrm{M}=-2.08, \mathrm{SD}=4.81)$ in the middle and the legislation-as-alternative condition with the highest intrusiveness rate $(n=235, \mathrm{M}=-0.82, \mathrm{SD}=4.91)$. A Sidak post-hoc test shows that the participants in the legislation-as-alternative condition rated the scenarios as significantly more intrusive compared to both the control condition (mean difference: $1.686, \mathrm{p}=0.005$ ) and the no-regulation condition (mean difference: 1.441, 


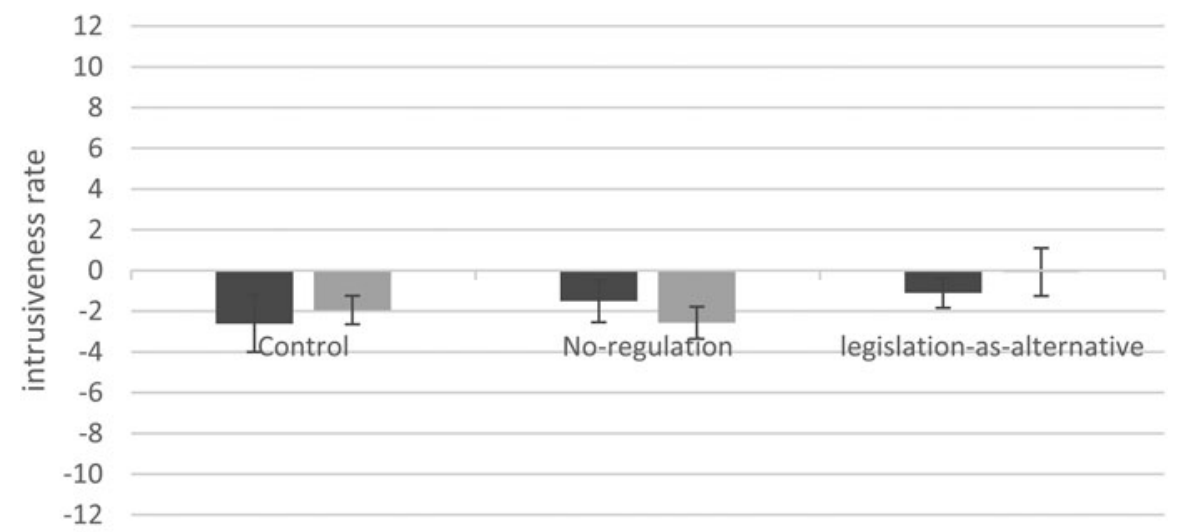

Passed manipulation check = Failed manipulation check

Figure 6. Intrusiveness rates for each condition and manipulation check. Error bars are $95 \%$ confidence intervals.

$\mathrm{p}=0.009$ ), and there is no difference between the other conditions (mean difference: $-0.244, p=0.9653$ ). No significant main effect of the manipulation check was found for intrusiveness rate $(\mathrm{F}(1,686)=0.248, \mathrm{p}=0.619, \eta=0.000)$ and no significant interaction effect between condition and manipulation check was found $(\mathrm{F}(2,686)=2.627, \mathrm{p}=0.073, \eta=0.008)$.

\section{Effect of pro-social versus pro-self domain}

Data pooled across all conditions for the two scenarios a priori categorized as pro-self showed a higher acceptance rate $(n=692, \mathrm{M}=2.47, \mathrm{SD}=2.49) \mathrm{com}$ pared to two scenarios a priori categorized as pro-social $(n=692, \mathrm{M}=1.65$, $\mathrm{SD}=3.15)(\mathrm{t}(691)=-6.822, \mathrm{p}<0.001, \mathrm{~d}=0.260)$.

Furthermore, as can be seen in Figure 7 , the pro-self scenarios had a significantly greater acceptance rate $(n=230, \mathrm{M}=2.64, \mathrm{SD}=2.39)$ compared to pro-social scenarios $(n=230, \mathrm{M}=1.86, \mathrm{SD}=3.10)$ in the control condition $(t(229)=-3.928, p<0.001, d=0.260)$. The pro-self scenarios also had a significantly greater acceptance rate $(n=227, \mathrm{M}=2.77, \mathrm{SD}=2.49)$ compared to pro-social scenarios $(n=227, \mathrm{M}=1.84, \mathrm{SD}=3.05)$ in the no-regulation condition $(\mathrm{t}(226)=-4.406, \mathrm{p}<0.001, \mathrm{~d}=0.293)$, and pro-self scenarios $(n=235$, $\mathrm{M}=2.02, \mathrm{SD}=2.52$ ) had a significantly greater acceptance rate compared to pro-social scenarios $(n=235, \mathrm{M}=1.26, \mathrm{SD}=3.27)$ in the legislation-as-alternative condition $(\mathrm{t}(234)=-3.503, \mathrm{p}=0.001, \mathrm{~d}=0.229)$.

Pro-self scenarios (data pooled across all conditions for the two scenarios a priori categorized as pro-self) had a greater intrusiveness rate $(n=692$, 
The effect of paternalistic alternatives on attitudes toward default nudges 111

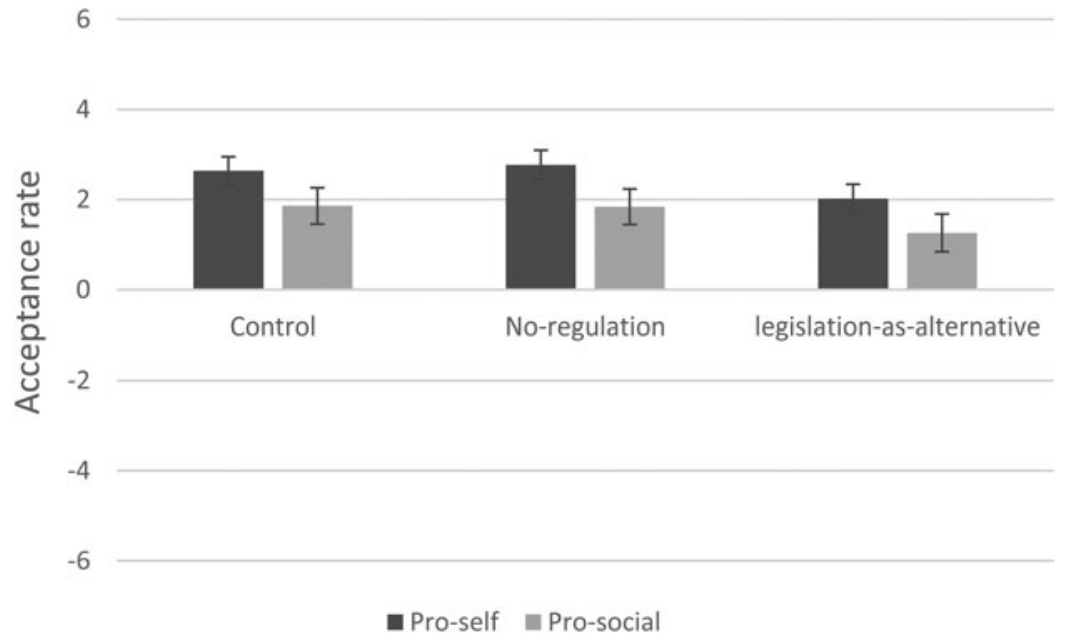

Figure 7. Acceptance rates of pro-social and pro-self nudges divided by condition. Error bars are $95 \%$ confidence intervals.

$\mathrm{M}=-1.31, \mathrm{SD}=2.65)$ compared to the two scenarios a priori categorized as pro-social $(n=692, \mathrm{M}=-0.37, \mathrm{SD}=3.09)(\mathrm{t}(691)=-8.142, \mathrm{p}<0.001$, $\mathrm{d}=0.310)$.

Furthermore, as can be seen in Figure 8, the pro-self scenarios had a significantly greater intrusiveness rate $(n=230, \mathrm{M}=-1.54, \mathrm{SD}=2.54)$ compared to pro-social scenarios $(n=230, \mathrm{M}=-0.53, \mathrm{SD}=3.13)$ in the control condition $(\mathrm{t}(229)=-5.016, \mathrm{p}<0.001, \mathrm{~d}=0.331)$. The pro-self scenarios also had a significantly greater intrusiveness rate $(n=227, \mathrm{M}=-1.60, \mathrm{SD}=2.65)$ compared to pro-social scenarios $(n=227, \mathrm{M}=-0.58, \mathrm{SD}=3.05)$ in the no-regulation condition $(\mathrm{t}(226)=5.098, \mathrm{p}<0.001, \mathrm{~d}=0.339)$, and pro-self scenarios $(n=235$, $\mathrm{M}=-0.80, \mathrm{SD}=2.69$ ) had a significantly greater intrusiveness rate compared to pro-social scenarios $(n=235, \mathrm{M}=-0.02, \mathrm{SD}=3.05)$ in the legislation-asalternative condition $(\mathrm{t}(234)=3.979, \mathrm{p}=0.001, \mathrm{~d}=0.260)$.

\section{Effects of individual differences}

In order to investigate individual factors that may affect acceptance rates, a multiple regression was conducted (Table 5). In the regression, a dummy variable for the no-regulation condition (1/0) and the legislation-as-alternative condition (1/0), manipulation check (1/0) and a dummy variable for higher education $(1 / 0)$ were included, along with control variables for age, gender, individualism, egalitarianism, intuitive decision style and rational decision style. 
6

4

2

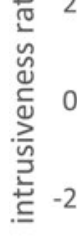

$-4$

$-6$

\section{Pro-self a Pro-social}

Figure 8. Intrusiveness rates of pro-social and pro-self nudges divided by condition. Error bars are $95 \%$ confidence intervals.

Table 5. Linear regression analyses exploring the influences of individual differences on acceptance rate.

Confidence interval

$\beta \quad$ Lower bound Upper bound $\beta$ (standardized) p-value

\begin{tabular}{lrrrrr}
\hline No-regulation (dummy) & -0.264 & -1.073 & 0.546 & -0.026 & 0.523 \\
Legislation (dummy) & -1.733 & -2.620 & -0.847 & -0.174 & $<0.001$ \\
Manipulation check & 0.901 & 0.166 & 1.637 & 0.095 & 0.016 \\
Higher education (dummy) & -0.214 & -0.899 & 0.472 & -0.023 & 0.541 \\
Female & 0.511 & -0.168 & 1.191 & 0.054 & 0.140 \\
Age & -0.016 & -0.042 & 0.009 & -0.044 & 0.208 \\
Individualist & -0.522 & -0.623 & -0.420 & -0.379 & $<0.001$ \\
Egalitarian & 0.292 & 0.151 & 0.433 & 0.155 & $<0.001$ \\
Rational decision style & 0.065 & -0.052 & 0.182 & 0.041 & 0.276 \\
Intuitive decision style & 0.082 & -0.023 & 0.187 & 0.060 & 0.124 \\
& & & & &
\end{tabular}

The results show that $17.4 \%$ of the variance could be explained with four variables $(\mathrm{F}(9,677)=14.283, \mathrm{p}<0.001)$ where the acceptance rate was lower in the legislation-as-alternative condition $(\beta=-1.733, \mathrm{p}<0.001)$. The acceptance rate was also lower for more individualistic participants 
The effect of paternalistic alternatives on attitudes toward default nudges 113

Table 6. Linear regression analyses exploring the influences of individual differences on intrusiveness rate.

\begin{tabular}{lrrrrr}
\hline \hline \multicolumn{5}{c}{} & \multicolumn{2}{c}{ Confidence interval } \\
\cline { 3 - 4 } & $\beta$ & Lower bound & Upper bound & $\beta$ (standardized) & p-value \\
\hline No-regulation (dummy) & 0.166 & -0.680 & 1.012 & 0.016 & 0.700 \\
Legislation (dummy) & 1.370 & 0.443 & 2.297 & 0.133 & 0.004 \\
Manipulation check & -0.122 & -0.891 & 0.647 & -0.012 & 0.755 \\
Higher education (dummy) & 0.314 & -0.402 & 1.031 & 0.032 & 0.389 \\
Female & -0.124 & -0.834 & 0.587 & -0.013 & 0.733 \\
Age & 0.007 & -0.020 & 0.034 & 0.019 & 0.603 \\
Individualist & 0.547 & 0.441 & 0.654 & 0.384 & $<0.001$ \\
Egalitarian & -0.141 & -0.289 & 0.007 & -0.072 & 0.061 \\
Rational decision style & -0.084 & -0.207 & 0.039 & -0.051 & 0.179 \\
Intuitive decision style & -0.109 & -0.218 & 0.001 & -0.076 & 0.052 \\
& & & & \\
\hline \hline
\end{tabular}

$(\beta=-0.522, \mathrm{p}<0.001)$ and more egalitarian participants had a greater acceptance rate $(\beta=0.292, \mathrm{p}<0.001)$, along with the participants who answered correctly on the manipulation check $(\beta=0.901, \mathrm{p}=0.016)$, with no other significant effects for the other variables. The finding from Study 1 that more individualistic (and egalitarian) participants differed in their acceptance rating in the legislation-as-alternative condition compared to the other conditions was not replicated.

A similar analysis was run for intrusiveness (Table 6). The results show that $16.0 \%$ of the variance could be explained with two variables $\left(\mathrm{R}^{2}=0.160, \mathrm{~F}(9,677)=12.938, \mathrm{p}<0.001\right)$. The intrusiveness rate was greater in the legislation-as-alternative condition $(\beta=1.370, \mathrm{p}=0.004)$ and the intrusiveness rate was also higher for more individualistic participants $(\beta=0.547, \mathrm{p}<0.001)$, with no other significant effects for the other variables. The finding from Study 1 that more individualistic (and egalitarian) participants differed in their intrusiveness rating in the legislation-as-alternative condition compared to the other conditions was not replicated.

In summary, Study 2 replicates and strengthens the findings from Study 1 that, contrary to our original predictions, the legislation-as-alternative condition was rated as least accepted and as most intrusive. We find that this pattern holds for both pro-social and pro-self scenarios. Importantly, the main effect including all participants (an intention-to-treat analysis) holds for both participants who answered the manipulation check correctly and for the participants who answer incorrectly. Even if we find a main effect of the manipulation check question with participants who answered correctly 
rating acceptance as higher, the general pattern that legislation as alternative is least accepted holds for both groups of participants.

\section{General discussion and conclusions}

In this study, we set out to examine whether providing explicit information about the alternatives to nudges would change the acceptability of nudges. We expected that making legislation a salient alternative would make nudges more acceptable compared to providing no information or giving information that everything would stay the same (since the nudge would be a less paternalistic alternative compared to legislation). However, we found no difference in acceptance when we provided explicit information about the alternative and an effect in the opposite direction for perceived intrusiveness to freedom of choice in Study 1. We replicated and strengthened these findings in Study 2 using both a different dependent variable (interval scale rather than binary choice) and manipulation checks. In Study 2, we found that the legislation-as-alternative condition was rated as the least accepted and most intrusive (both for participants who passed and those who failed the manipulation check). Thus, two studies using large representative samples show results that are opposite to what we predicted. How can these results be understood?

One interpretation of our results is that the respondents might use a form of heuristic responding induced by the alternative. Relevant here is the affect heuristic (Slovic et al., 2002; Slovic \& Västfjäll, 2010), which has shown that people, instead of using careful analysis, rely on their feelings when making judgments (Västfjäll et al., 2014, 2016). For instance, when people are asked to judge the risk versus benefit of an activity, they draw on their general affective feelings (good/bad) for the activity rather than carefully analyzing the pros and cons of that activity. Slovic et al. (2002), for instance, found that people used the affect heuristic when making judgments about the risks and benefits of activities and technologies (e.g., nuclear power). A main finding was that people who associate negative feelings with nuclear energy see the technology as having little benefit and of high risk. People who instead have positive feelings associated with nuclear energy judge the activity to be beneficial and of low risk. It is possible that our manipulation worked in a similar way: simply presenting the nudge together with legislation (something that people could possibly associate with negative feelings) decreases the attractiveness of the nudge. Similarly, presenting a nudge next to the status quo alternative (nothing would happen), which arguably most people who dislike paternalism would associate with positive feelings, could spill over to the nudge, effectively making it more attractive. 
Another possibility is that salient alternatives may be used in different ways by different individuals. It is likely that some individuals favor legislation and therefore might be willing to reject the nudge. If people think the behavior is important enough to promote, then they might find the tradeoff between paternalism and efficiency to be fine, assuming that most people think that legislation is more effective then nudges. This could be especially relevant to the Swedish context, where citizens historically have had a high level of trust that the government will act in the best interests of its citizens. Effectiveness has been shown to increase the acceptance of nudges (Petrescu et al., 2016). If the group that accepts the nudge in the legislation-as-alternative condition (to avoid legislation) is of similar size to the group that would rather see legislation instead of a nudge (i.e., rejecting the nudge in favor of legislation), the net effect would be zero. If this was the case, then this should be possible to capture indirectly with our individualistic measure. In Study 1, we found that that more (compared to less) individualistic participants had a lower level of acceptance for nudges in the control and no-regulation scenarios, and acceptance was highest when legislation was the alternative. However, the pattern is reversed for less individualistic participants. In Study 2, we instead found that, overall, more individualistic participants were less accepting across the manipulations (replicating Hagman et al., 2015). These findings suggest that individual differences (especially individualistic versus collectivistic worldviews) are important for general acceptance and perceived intrusiveness of nudges and that, furthermore, individual differences may sometimes interact with information about policy alternatives. Thus, an important lesson for policy is that 'one nudge does not fit all' (Hagman et al., 2015) - that sometimes the same information will be differently received by different people. This result is consistent with previous research showing the importance of worldviews/values for attitudes toward nudges (Hagman et al., 2015; Jung \& Mellers, 2016) and also relates to the notion that the political affiliation of the sender proposing a nudge, as well as the worldview of the receiver of the nudge policy, jointly determine acceptability (Tannebaum et al., 2017).

Importantly, though, we replicate the finding that pro-self nudges overall are more acceptable compared to pro-social nudges (Hagman et al., 2015). Thus, in spite of the overall high level of acceptance of nudges (Sunstein, 2017a), interventions aimed at promoting predominantly private welfare are preferred over interventions aimed at promoting predominantly social welfare. This finding suggests that policy-makers will be more successful in implementing pro-self nudges. Additionally, information campaigns highlighting the benefit for the individual rather than society may increase acceptance of policy changes. 
An important possible limiting condition for this research is that we only conducted our studies in a Swedish sample. Even though previous research has reported a rather homogenous view on different nudges in Europe (Sunstein, 2017a) or when comparing Swedish and US samples (Hagman et al., 2015), it is very possible that the effect of more paternalistic alternatives would be different in societies that are more focused on individualistic motives. Sweden has had a longstanding tradition involving a strong welfare state emphasizing collective and uniform solutions throughout the public sector. In contrast, the political discourse in, for example, the USA has traditionally emphasized more liberal values related to freedom of choice. Thus, an important task for future research is to examine whether the effects of alternatives found in a Swedish context translate to other cultures.

In summary, this study set out to demonstrate that comparing a nudge to an explicit alternative that is more paternalistic (legislation) or less paternalistic (no regulation at all) should systematically affect acceptability. However, we found surprisingly little effect on the overall acceptance of nudges regardless of the alternative, and when we found an effect, it was in the opposite direction to our prediction - when the alternative to the nudge is legislation, acceptance decreases. While these findings must be replicated and extended, an interesting implication of our study is that acceptance of nudges may not always automatically increase when legislation is added as an alternative or used as a reference point.

\section{Acknowledgments}

This research was funded by the Länsföräkringar Research Alliance, grant P15/02 awarded to Daniel Västfjäll.

\section{References}

Arad, A. and A. Rubinstein (2017), 'The People's Perspective on Libertarian-Paternalistic Policies' The Journal of Law and Economics, 61, 2.

Bazerman, M. H., G. F. Loewenstein and S. B. White (1992), 'Reversals of preference in allocation decisions: Judging an alternative versus choosing among alternatives' Administrative Science Quarterly, 220-240.

Bovens, L. (2009). The ethics of Nudge, In T. Grüne-Yanoff and S.O. Hansson eds., (2009), Preference change: Approaches from philosophy, economics and psychology (Vol. 42), Springer Science \& Business Media.

Davidai, S. and E. Shafir (2018), 'Are 'nudges' getting a fair shot? Joint versus separate evaluation' Behavioural Public Policy, 1-19.

Felsen, G., N. Castelo and P. B. Reiner (2013), 'Decisional enhancement and autonomy: public attitudes towards overt and covert Nudges' Judgment and Decision Making, 8(3): 202. 
Frederick, S., N. Novemsky, J. Wang, R. Dhar and S. Nowlis (2009), 'Opportunity cost neglect' Journal of Consumer Research, 36(4): 553-561.

Hagman, W., D. Andersson, D. Västfjäll and G. Tinghög (2015), 'Public views on policies involving Nudges' Review of Philosophy and Psychology, 6(3): 439-453.

Halpern, D. and M. Sanders (2016), 'Nudging by government: Progress, impact, \& lessons learned' Behavioral Science \& Policy, 2(2): 52-65.

Hamilton, K., S. I. Shih and S. Mohammed (2016), 'The development and validation of the rational and intuitive decision styles scale' Journal of Personality Assessment, 98(5): 523-535.

Hausman, D. M. and B. Welch (2010), 'Debate: To nudge or not to nudge' Journal of Political Philosophy, 18(1): 123-136.

Hsee, C. K., G. F. Loewenstein, S. Blount and M. H. Bazerman (1999), 'Preference reversals between joint and separate evaluations of options: a review and theoretical analysis' Psychological bulletin, 125(5): 576.

Hsee, C. K. and J. Zhang (2010), 'General evaluability theory' Perspectives on Psychological Science, 5(4): 343-355.

Jung, J. Y. and B. A. Mellers (2016), 'American attitudes toward nudges' Judgment and Decision Making, 11(1): 62-74.

Kahan, D. M. (2014), Cultural cognition as a conception of cultural theory of risk. In Handbook of risk theory, ed. S. Roeser. Dordrecht: Springer, 725-759.

Kahan, D. M. and D. Braman (2006), 'Cultural cognition and public policy' Yale Law \& Policy Review, 24(1): 149-172.

Kahneman, D. (2011), Thinking, fast and slow, Macmillan.

Kahneman, D. and A. Tversky (1979), 'Prospect theory: An analysis of decision under risk' Econometrica, 47(2): 263-292.

Loibl, C., C. R. Sunstein, J. Rauber and L. A. Reisch (2018), Which Europeans like nudges? Approval and controversy in four European countries. Journal of Consumer Affairs. https:/doi.org/10. 1111/joca.12181

Page, B. I. and R. Y. Shapiro (1983), 'Effects of public opinion on policy' American political science review, 77(1): 175-190.

Petrescu, D. C., G. J. Hollands, D. L. Couturier, Y. L. Ng and T. M. Marteau (2016), 'Public acceptability in the UK and USA of nudging to reduce obesity: the example of reducing sugar-sweetened beverages consumption' PLoS One, 11(6): e0155995.

Reisch, L. A., C. R. Sunstein and W. Gwozdz (2017), 'Beyond carrots and sticks: Europeans support health nudges' Food Policy, 69, 1-10.

Reisch, L. A. and C. R. Sunstein (2016), 'Do Europeans like nudges? Judgment and Decision Making, 11(4): 310-325.

Slovic, P., M. Finucane, E. Peters and D. G. MacGregor (2002), 'Rational actors or rational fools: Implications of the affect heuristic for behavioral economics' The Journal of SocioEconomics, 31(4): 329-342.

Slovic, P. and D. Västfjäll (2010), 'Affect, moral intuition, and risk' Psychological Inquiry, 21, 387 398.

Sunstein, C.R. (2016), 'People prefer System 2 nudges (kind of)' Duke Law Journal, 66(1): 121-168.

Sunstein, C. R. (2017a), Human Agency and Behavioral Economics: Nudging Fast and Slow, Springer.

Sunstein, C. R. (2017b), 'Default rules are better than active choosing (Often)' Trends in Cognitive Sciences, 21(8): 600-606.

Szaszi, B., A. Palinkas, B. Palfi, A. Szollosi and B. Aczel (2017), 'A Systematic Scoping Review of the Choice Architecture Movement: Toward Understanding When and Why Nudges Work' Journal of Behavioral Decision Making, doi: 10.1002/bdm.2035. 
Tannenbaum, D., C. R. Fox and T. Rogers (2017), 'On the Misplaced Politics of Behavioral Policy Interventions' Nature Human Behaviour, 1, doi:10.1038/s41562-017-0130

Thaler, R. H., and C. R. Sunstein (2008), Nudge: improving decisions about health, wealth and happiness, New Haven: Yale University Press.

Tversky, A. and D. Kahneman (1992), 'Advances in prospect theory: Cumulative representation of uncertainty' Journal of Risk and Uncertainty, 5(4): 297-323.

Västfjäll, D., E. Peters and P. Slovic (2014), 'The affect heuristic, mortality salience, and risk: Domainspecific effects of a natural disaster on risk-benefit perception' Scandinavian Journal of Psychology, 55, 527-532.

Västfjäll, D., P. Slovic, W. Burns, A. Erlandsson, L. Koppel, E. Asutay and G. Tinghög (2016), 'The arithmetic of emotion: Integration of incidental and integral affect in judgments and decisions' Frontiers in Psychology, 7. doi: 10.3389/fpsyg.2016.00325

Whitehead, M., R. Jones, R. Howell, R. Lilley and J. Pykett, (2014), 'Nudging all over the world. Reino Unido, Economic and Social Research Council, p.25.

Whitman, D. G. and M. J. Rizzo (2015), 'The problematic welfare standards of behavioral paternalism' Review of Philosophy and Psychology, 6(3): 409-425. 